\title{
Mobility as a Service (MaaS): Challenges of Implementation and Policy Required
}

\author{
Yanying $\mathbf{L i}{ }^{*}$, Tom Voege ${ }^{2}$ \\ ${ }^{1}$ ERTICO-ITS Europe, Brussels, Belgium \\ ${ }^{2}$ International Transport Forum at OECD, Paris, France

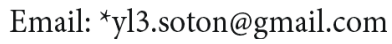

How to cite this paper: Li, Y. and Voege, T. (2017) Mobility as a Service (MaaS): Challenges of Implementation and Policy Required. Journal of Transportation Technologies, 7, 95-106.

https://doi.org/10.4236/jtts.2017.72007

Received: December 20, 2016

Accepted: March 10, 2017

Published: March 13, 2017

Copyright (c) 2017 by authors and Scientific Research Publishing Inc. This work is licensed under the Creative Commons Attribution International License (CC BY 4.0).

http://creativecommons.org/licenses/by/4.0/

\begin{abstract}
Mobility as a service (MaaS) is a relatively new concept, which holds the promise for a paradigm shift in the provision of urban mobility. The concept of MaaS is to use a single app to access and pay for various transport modes within a city or beyond; and the app will give options to allow a traveller to select the most suitable transport mode. The concept of MaaS is enabled by the current mass uptake of smartphones and social media as well ubiquitous internet connection. By studying current applications of MaaS in Europe and US conditions of operation of MaaS have been summarised. Based on the necessary conditions, a checklist has been developed for potential developers of MaaS to assess if they can implement MaaS in a city. This paper also discusses challenges of implementation of MaaS and their potential impacts on urban mobility and societal changes.
\end{abstract}

\section{Keywords}

Mobility as a Service (MaaS), Urban Mobility, Travel App

\section{Introduction}

Traditionally, a traveller needs different tickets for different transport modes and/or different operators. In recent years, public transport operators have made considerable efforts to provide a single public transport ticket to allow a traveller to use public transport services from different transport operators in the same city or region. However, recently also many new transport service provisions have entered the market, such as bicycle sharing, car sharing and ride sharing. Usage of those new transport modes are accelerated by increasing concerns from users for sustainability and environment. In addition, changes in lifestyles of younger generations and people who choose to live in cities rather than the traditionally suburban life style, which depends on private car as the main transport 
mode. Owning a car is no longer a "must have" lifestyle choice, particularly in high income countries. Rocky Mountain Institute [1] forecasts that car ownership levels in the United States will peak around 2020 and will drop quickly after that. Car makers are capitalising on emerging business models to position themselves also as mobility service providers. Their business shifts towards car sharing services, e.g. Car2 Go from Daimler [2] and Drive Now from BMW [3]. Transport policy makers have tried for years to make public transport more attractive in order to enable modal shift from private cars. Such modal shift now has been realised mainly through new technologies.

Modern mobility should offer a high level of flexibility and convenience. In an UITP position paper 2011 [4], the public transport operator association has already forecasted that combining various transport modes, e.g. car-sharing, taxi, shared taxis, bicycle and bike-sharing, car-pooling, demand-responsible transport can complement the classic fixed lined and routed public transport. The changes in personal mobility markets have presented great opportunities to urban mobility and new players, e.g. travel brokers, enter the market. Travel brokers have developed smartphone based apps to integrate available transport modes and to enable seamless multi-modal travel. Such an app offers its users one-stop access to a wide range of travel services through a single app. Such an app may simply just allow users to get information on various options and use the same account to pay the chosen service, e.g. Go Denver in US [5]. However, some apps are built up as a monthly subscription service when a user or a household decided their desired combination of transport and associated amount, such as UbiGo in Gothenburg, Sweden [6]. Mobility as a Service (MaaS) often refers to the latter one.

The changes in personal mobility markets also have shifted roles of public authorities. Public authorities are moving beyond its conventional role as infrastructure providers by enabling and promoting the mobility services of nonconventional providers. Public authorities and public transport companies are now using the services of new enterprises and new platforms in order to reduce the need for costly investments in new transport infrastructure, equipment and operation systems.

\section{The Concept of MaaS}

The monthly or yearly subscription of public transport, i.e. season ticket, is widely used in many cities and regions. Often, such season ticket offers unlimited use of various public transport services in a city or a region, e.g. commuter train, metro and bus, even though the public transport services may be provided by different operators. Daily, weekly and monthly subscription of bicycle sharing is also available. For example, Vélib in many French cities offers the monthly subscription with which a rental bicycle can be used free-of-charge for half hour per day [7]

Some cities allow using pre-paid public transport cards to use other transport services, e.g. the public transport card, MetroCard, in Shanghai [8] can also be used to pay taxis. However, the monthly subscription of combination of various 
transport services not widely used yet. The revolution MaaS has brought to the personal mobility market is a monthly subscription combining various transport services. With a package of MaaS, a user can have e.g. unlimited usage of public transport, a number of taxi trips, a number of days using car rental, etc.

Such business model is inspired by the business model of the current personal communication market. In the old times, phone bills were paid based on usage. Then mobile phone companies started to offer a package including a number of calls and texts. Now in Europe, some mobile phone companies offer a package including a number of calls, texts and usage of internet. There are subscriptions which cover local and roaming in other countries. MaaS simply takes the subscription model into the transport market.

Although current MaaS is still operated at a local level much effort is being made into turning MaaS as a global solution. MaaS Global, a company in Finland, has claimed that its App, Whim, is the first MaaS solution in the world [9]. Currently Whim in Helsinki offers four types of MaaS services, i.e. Light, Medium, Premium and Pay-as-you-go. All services include unlimited usage of public transport and a number of taxi rides. Medium and Premium services include 2 and 5 day rental car usages respectively. Different types of the monthly subscription of Whim are shown in Figure 1. An update of $50 €$ can cover a wider area of Helsinki. Whim can synchronise with smartphone calendar and make travel plans for users accordingly.

UbiGo in Gothenburg, Sweden, covers a wider range of transport modes than Whim in Helsinki. In addition to public transport, taxi and car rentals, UbiGo also offers one stop access to car-sharing and bicycle-sharing. The subscription can be modified on a monthly basis according to personal needs at different periods of a year.

Different from the two services in Scandinavian countries, "Go Denver" in US only offers an integrated travel plan service with single payment. A user can use the service to find various route options and use the app to the chosen option. Go Denver may be considered as a basic version of MaaS. Since there is no subscription for the service, a different business model from MaaS is applied. The provider of the service may profit from analysing users' data.

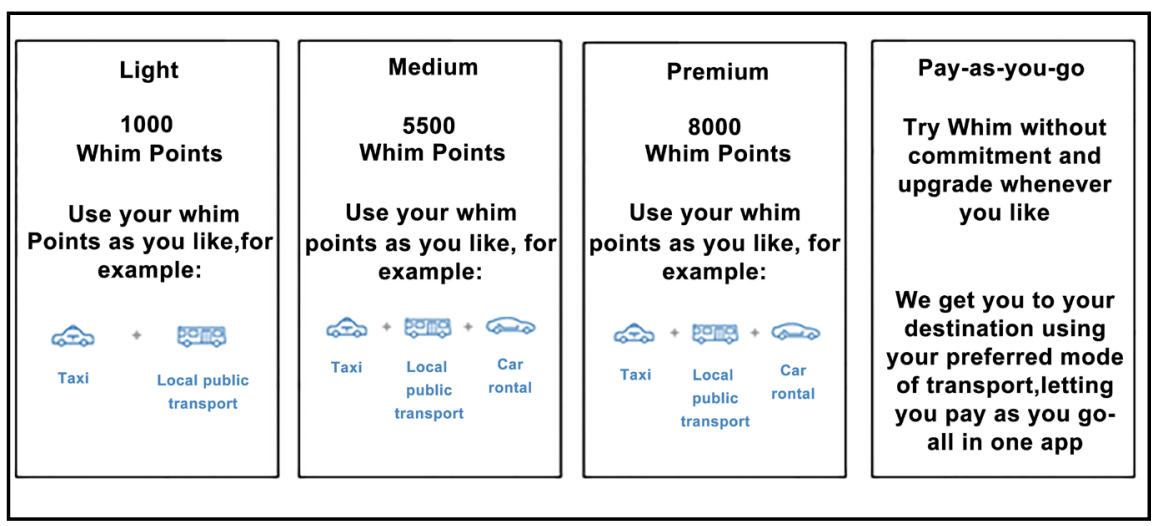

Figure 1. Different types of the monthly subscription of Whim. 
Currently all available MaaS services target local residents, i.e. commuters, even though MaaS may offer great value also to visitors to a city. A visitor may feel difficulties to understand local public transport systems and to buy tickets. Although Google map and other map providers offer information on public transport in most major cities worldwide, travellers, particularly business travellers often go for the easiest options, e.g. taking a taxi or renting a car, in an unfamiliar city. Taxi or car rental is not only expensive, in some cases, they may not be the best option, e.g. if the city is congested, has limited parking spaces or restrict access control. Thus, a traveller may find himself/herself in a stressful situation in a city even though the city has excellent public transport services.

There is a vision to enable a user to use the same app to travel in different cities worldwide and to have the same level of services as in the home city. Uber [10] has realised the vision for taxi services. A user of Uber can use the same app to call an Uber car in anywhere in the world where Uber services are available without being worried about costs and different currency. To realise the vision of global availability for MaaS, the MaaS Alliance [11] has been created in 2015, which is a public-private partnership, aiming to creating the foundation for the mass market uptake of MaaS in Europe and beyond. Much of the current work of the MaaS Alliance is focused on openness and interoperability of data, roaming cost, billing and clearing, business rules of different actors.

\section{The Conditions to Operating MaaS}

Despite different business models, implementing and operating a MaaS service requires a single identity for a user, open data and open payment methods from various transport modes. If a transport operator is not willing to use third party's payment to buy its ticket or to not allow third party to sale its tickets on their behalf services of the transport operators cannot be included in MaaS. In many countries public transport tickets have been heavily regulated and no third party is allowed to sell tickets rather than the operator itself. Within such legal framework, integrated ticketing of various modes may not be possible, thus MaaS is also not feasible.

Operating MaaS requires a single identity for a traveller to travel with different modes. This is not a new concept. In the air transport sector, a paper ticket or a physical ticket had disappeared for years. An air traveller uses his/her identity to access air transport services without carrying any physical tickets. Since air travel requires ID documents for security reason, such ticketless travelling is a consequence of the nature of the air travel. In recent years, railway ticketing also has been upgraded to electronic ticketing, although paper tickets are still in use. A railway passenger can buy a railway ticket and save the QR data on a smartphone which can be inspected by train conductors. Some train companies, e.g. Thalys, an international high speed train operator in Europe, offers its passengers to book and travel using their frequent traveller cards only. Yet most surface transport modes in cities do not require a user to carry ID while travelling, using single identity for traveller may be challenging. However, very often 
people say that "they often forget their public transport cards but they rarely forget their mobile phones" [12]. In another word, smart phones have become people's new "ID". Therefore, using the new "ID" to travel through different transport modes in a city is feasible.

There are some basic conditions which must be met in order to develop and operate MaaS. Conditions to operating MaaS in a city may be summarised as below:

- A wide range of transport modes are available in the city;

- Majority of the transport operators a open their data including real-time data to a third party;

- Majority of the transport operators allow a third party to sell their service;

- Majority of the transport operators offer e-ticket or e-payment to access their services.

MaaS would only be operated in a city when the city offers different transport modes. Since public transport still is at the centre of MaaS, a city must have adequate public transport services to allow users to travel in the city easily without having to own a car. In another word, MaaS may only be operated in a place where users are willing to move away from car-dependent daily transport. That is often in a city where public transport services are already quite good and many residents do not see the essentials of owning a car. Some earlier trials, e.g. UbiGo, aimed to encourage modal shifts. However, Gothenburg is a city which offers great public transport services and sustainable urban mobility is at the centre of the city's transport policy. The transport policy and city's existing transport services have prepared the ground for the implementation of UbiGo. MaaS is seen as an alternative choice to owning a car while enjoying equally convenient transport services. MaaS may also be used in lower income countries to provide mobility solutions to those who cannot afford owning a car.

Traditionally traveller information provision is a responsibility of a transport operator. Recently, many transport operators choose to open their data to allow developers to implement information services. Making public transport data open to developers has huge impacts on traveller information provisions. For example, publishing the public transport data in Helsinki has boosted the market of apps for journey planners in the city. Just in Google Play, the app store for smart phones using the Android operation system, there are more than 30 apps of Helsinki's multimodal journey planners [13]. The open data policy may also be a catalyst of the implementation of MaaS in Helsinki. While many public transport operators have made their real time data available, operators of other transport modes rarely open their data to third party developers. For example, real time data on bicycle sharing, e.g. location of bicycle stations, availability of parking slot and bicycles at each station, has rarely been made available for app developers. If a MaaS provider is planning to include bicycle sharing in the service, the provider must access real-time data at each bicycle sharing station to enable its user to rent a bicycle or to return a rental bicycle. Moreover, current taxi apps allow a user to track his/her reserved vehicle's location. MaaS will have 
to offer the equivalent services when a MaaS subscriber chooses the taxi service. It means that the taxi company must allow MaaS to access its real time operation data. It can be foreseen that if MaaS becomes main stream travellers' choice, more transport operators would be willing to share their data with MaaS developers. However, at this stage, to enable all transport operators to make their data available for MaaS developers remains challenging.

A key success factor of MaaS is to use single account to pay all transport services. A user of MaaS does not need to have different cards, different accounts or individual payments. Without MaaS, a user may have an Uber app and a local taxi app, even though the two apps are in the same smartphone and may use the same credit card for payment. Currently there are huge numbers of apps for transport services available in app stores. For example, there are more than 60,000 travel apps available in Google Play [14]. With MaaS, the user can have only one app to replace a number of transport apps. There have been increasing concerns about the negative impacts of MaaS on competition of travel app services and provision of innovative transport modes. Since many apps are developed by Small and Medium-sized Enterprises (SMEs), MaaS may be seen as a threat to SMEs in the travel app market.

One essential condition to operating MaaS is that smartphones can be used to access various transport modes. That means that operators of those transport modes must allow various forms of e-ticket or e-payment. For example, a MaaS app can be inspected by a conductor to prove the traveller has paid for his/her journey. If a user has chosen shared bicycle, a MaaS app should be able to release a bicycle from the parking slot. Public transport often requires tickets to go through physical barriers. MaaS may only be used when a public transport provider allows passing the physical barriers by scanning smartphones. Additional investments into infrastructure may be required. Whether or not a transport operator is willing to pay for such additional cost is a challenge for MaaS providers.

The following Figure 2 shows a checklist to analyse if a MaaS can be implemented in a city. A MaaS service in a city may be initiated by the local authority of the city as an instrument to make urban mobility in the city more sustainable. However, MaaS may also be operated in a city without official supports of the local authorities when the basic conditions mentioned above have been met.

\section{Discussions on Potential Challenges of MaaS}

If all conditions above have been met in a city, implementation of MaaS still faces significant challenges on users' perspectives, business model and policy support, even though MaaS has been seen by transport professionals as potentially enabling a paradigm shift towards more sustainable urban mobility. There is no doubt that MaaS does have great potentials to offer convenient and comfortable travels in a city without owning a car. Maas can help a user to plan their journeys based on the user's calender, thus providing the user with stress-free travel planning. Implementation of MaaS at a local level can make even more people 


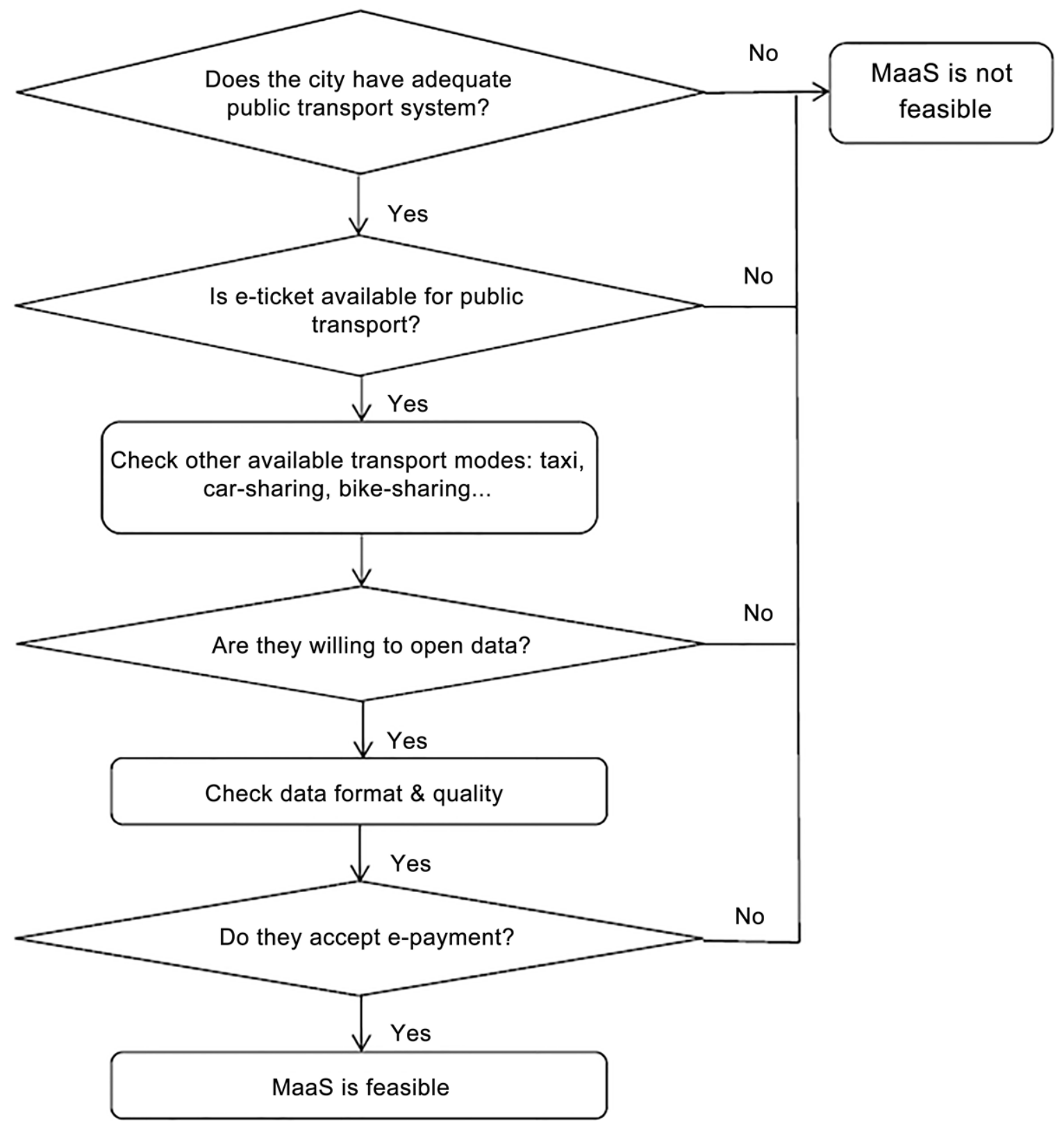

Figure 2. Check list of operating MaaS in a city.

choose sustainable transport modes rather than using private cars. Researchers in Gothenburg have concluded that $93 \%$ of participants were satisfied with their travel and 97\% wanted to continue using UbiGo [15].

However, if a MaaS service only targets local customers, the benefits may be limited. Firstly, decreasing car ownership levels have been observed in big cities due to changes of lifestyles, increasing concerns about sustainability and health and improved services and facilities for sustainable transport modes, e.g. widely available real time public transport information, dedicated cycling lanes, etc. Those, who do not have private cars and travel by public transport, use shared 
cars and cycle to work, are often familiar with various transport option in the local areas and aware of all potential options and costs. They are also the generation who knows how to find information through the internet. They may have installed hundreds of apps to help them plan their journeys and pay for their journey. To a certain degree, a user can today already travel only with his/ her smart phone to access many transport services. Notable examples are car-sharing and taxi apps. Therefore, to make a user shift from familiar travel apps to one single app is a challenge for MaaS providers. Yet the users' perspectives toward MaaS have not been well studied and understood.

Even when MaaS would aim at a Pan-European or global market, i.e. to provide MaaS for a user wherever the user travels MaaS may still face strong competitions from existing travel apps which have already offered global services. Beside the famous Uber app, eCab, a taxi app, also offers taxi booking and payment services using one single account in 6 European countries as well as in India, Canada and Lebanon. A MaaS service will have to work with existing providers, e.g. eCab, instead of attempting to integrate individual taxi companies again. It remains unclear whether such providers are willing to integrate their platforms with MaaS. That will have to depend on the growth of the MaaS market.

As mentioned before, if MaaS would become the main-stream travel app, various transport operators and service providers would be willing to share their data and services with MaaS providers. A good example is Google Transit. For many years, various government efforts have been made and research projects have been conducted into unified public transport data format. Despite of the efforts, public transport companies were still not willing to abandon their own data formats. However, when Google Transit becomes widely available, many transport operators voluntarily supply their data following the pre-defined data format following Google Transit. There are two reasons to enable public transport operators to work with Google Transit. One is that they want their public transport services to be included in Google map and navigation services which enjoy a dominant position worldwide. The second reason is that Google Transit APIs, General Transit Feed Specification (GTFS) and GTFS Real Time [16], are simple and user-friendly. MaaS providers should learn from Google Transit and develop user-friendly feed APIs to allow individual operators to join MaaS simply and easily. That would require pre-defined data formats and quality check mechanism. MaaS currently works on an open, standard-based system architecture. However, the issues of data formats and quality checks have not yet been addressed. Data quality is more essential for MaaS since it will have direct impacts on customers' experiences. Different from Google Transit, which is freeof-charge to users, MaaS must guarantee quality of information in order to build and maintain customers' confidence.

There are increasing concerns about competitiveness of the MaaS market. Currently, MaaS is still operated at a local level. When MaaS is extended to the global market, SMEs that are in the travel information and app services may face unfair competitions from big players. MaaS may also be a threat to innovation in 
the urban mobility market, which has seen many innovative solutions in the past few years. As sharing economy may continue to play an important role in many aspects of daily life, sharing economy in the mobility market will continue to influence people's choice of transport modes. While current MaaS does include car-sharing and ride-sharing in its services the growing new transport modes of the sharing economy will have impacts on the future MaaS market.

\section{Policy Framework for Implementation of MaaS}

Open data and use of ICT in urban services have been policies of many cities within the policy framework of smart cities. In the transport service market, integration of data and payments from various transport modes will improve further. Therefore, the foundation of implementation of MaaS will exist in many cities. However, implementation of MaaS in a city may face challenges in the financial aspect. Many cities subsidise their public transport services. If MaaS would make profits from its monthly subscriptions, it may not be able to make profits from sale of public transport tickets. If MaaS would make profits from sale of public transport tickets public transport companies may receive less incomes from users which would require more government subsidies. Government policy will have to define the business model of MaaS regarding public transport services.

In addition, many employers offer free public transport passes for their employees when they commute by public transport. Such passes may cover train if an employee lives in a suburban area and uses public transport. Often the employers/ employees can receive tax reduction for the commuting cost. If an employee would choose MaaS instead of a public transport pass, the employee may not be able to obtain the same subsidy or tax reduction. Therefore only when MaaS is identified by the local authorities as a type of sustainable transport mode with the same policy for government subsidy or tax reduction as other public transport modes, MaaS can be implemented in a city where subsidy and tax reduction is offered to those who commute by public transport.

\section{Discussion of MaaS's Roles in Future Mobility}

Currently MaaS targets young customers who use smartphones for information and payment. Benefits of MaaS in the ageing society have not been studied. Contrary to current targeted customers, the authors believe that MaaS would benefit elderly travellers more than younger ones. MaaS may be a good solution to meet travel demands of the aging society. Current research has shown more than $60 \%$ of elderly people in the UK own smart phones [17]. This is the first generation of elderly people who are used to smart phones and internet. Thus they will continue to use smartphones for their travel needs. A one-stop solution to access and pay for all types of transport modes would thus be an excellent solution for elderly travellers. Research also has shown that elderly travellers conduct more long trips [17] than younger ones. Therefore, MaaS covering home cities as well as oversea destinations would be welcome to elderly travellers who 
frequently travel abroad. In addition, MaaS may be seen as a travel companion that offers security and safety services at the same time. This can offer independence to elderly citizens, which is an important factor for enhancing quality of life.

In addition to all the previously mentioned reasons for moving to MaaS, the shift to a truly integrated shared mobility ecosystem will facilitate the transition to shared automated mobility. MaaS may be only fully realised when automated vehicles are available. Although automated vehicles have many potential benefits such as enhanced safety and efficiency, improved comfort and convenience levels for travellers and improved social inclusions, there is a possibility of increasing Vehicle Km Travelled (VKT) when using automated vehicles as personal vehicles, resulting in increasing congestion and energy consumption. Automated vehicles have been tested in Singapore as a Demand Responsive Transport solution [17]. Automated MaaS (A MaaS) will offer a great alternative to personal cars and will maximise the benefits of automated vehicles.

\section{Conclusions}

Personal urban mobility has been changed towards a smartphone, e-ticket and app based market. There are many new urban mobility solutions available which are sustainable such as ride sharing and car sharing. Often such solutions are enabled by updates of smartphone apps and ubiquitous internet connection. With the increasing options available in the urban mobility market, there is scope to combine all available options and to use a single app to access and pay for all transport modes. Mobility as a service (MaaS) is a relatively new concept, which holds the promise of providing a paradigm shift in urban mobility. The concept of MaaS is to use a single app to access and pay for various transport modes in a city or in a wide area and the app will give options to allow a traveller to select the most suitable transport options. Maas was initiated in Finland where public transport operators opened their data to app developers and allow e-tickets. MaaS is available as monthly subscription or pay-as-you-go. Enabling operation of MaaS in a city requires good public transport services, availability of various transport modes, open data and e-ticketing.

Operation of MaaS faces many challenges in users' perspectives, policy framework and business models. When attempting operation of MaaS in a pan-European or global scale, there are concerns on competitiveness of the mobility market which may have negative impacts on innovation and SMEs. There is a possibility that the global MaaS market may be dominated by few big players. Therefore, an appropriate policy framework which allows implementation of MaaS and benefits of MaaS to travellers, whilst at the same time preventing unfair competition is essential.

Although current targeted customers of MaaS are mainly the young generations who wish to adopt a sustainable lifestyle, MaaS may have great benefits to elderly travellers and play an important role to meet travel demand of the aging society. Moreover, MaaS may be the perfect solution when automated vehicles 
are available in the market. Automated MaaS (A-MaaS) will offer a great alternative to personal cars and will maximise the benefits of automated vehicles.

\section{Acknowledgements}

This research has been conducted as a part of the Viajeo Plus project which was a research project funded by the European Commission (EC) DG Research and Innovation through Framework Programme 7 (FP7). The authors wish to thank to $\mathrm{EC}$ and the project consortium for their support.

\section{References}

[1] Walker, J. and Johnson, C. (2016) Peak Car Ownership: The Market Opportunity of Electric Automated Mobility Services, Rocky Mountain Institute.

http://www.rmi.org/peak_car_ownership

[2] Car2Go (2016) https://www.car2go.com/US/en/

[3] Drive-Now (2016) https://drive-now.com/

[4] UITP (2011) Becoming a Real Mobility Provider Combined Mobility: Public Transport in Synergy with Other Modes Like Car-Sharing, Taxi and Cycling. http://www.uitp.org/becoming-real-mobility-provider-combined-mobility-public-tr ansport-synergy-other-modes-car-sharing

[5] Xerox Press Release (2016) Denver Pilots New Travel App with Xerox to Get a Grip on Urban Growth, Go Denver.

https://www.news.xerox.com/news/City-of-Denver-introduces-new-Xerox-Go-Den ver-app

[6] Sochor, J., Strömberg, H. and Karlsson, M. (2014) Traveller's Motives for Adopting a New, Innovative Travel Service: Insights from the UbiGo Field Operational Test in Gothenburg, Sweden. Proceedings 21 st World Congress on Intelligent Transport Systems, Detroit, 7-11 September 2014, ID: 13111.

[7] Vélib (2016) http://en.velib.paris.fr/

[8] Shanghai Metro (2016) http://service.shmetro.com/en/cpxz/index.htm

[9] MaaS Global (2016) http://whimapp.com/

[10] Crist, P., Voege, T. and Canales, D. (2016) Data-Driven Transport Policy. ITFOECD Report, Paris.

[11] The MaaS Alliance (2016) http://maas-alliance.eu/

[12] Sochor, J., Strömberg, H. and Karlsson, M. (2015) An Innovative Mobility Service to Facilitate Changes in Travel Behavior and Mode Choice. Proceedings 22nd World Congress on Intelligent Transport Systems, Boudreaux, 5-9 October 2015, ID: ITS1452.

[13] Li, Y. and Kristense, J. (2014) Transport Data Marketplace: An Analysis of User Requirements. Proceedings 10th European Congress on Intelligent Transport Systems, Helsinki, 16-19 June 2014, ID: 11491.

[14] Li, Y. (2015) Where to Find Mobility Related Apps: Designing an App Directory for Mobility Services. Proceedings 22nd World Congress on Intelligent Transport Systems, Boudreaux, 5-9 October 2015, ID: ITS-1800.

[15] Sochor, J., Strömberg, H. and Karlsson, M. (2015) Implementing Mobility as a Service: Challenges in Integrating User, Commercial, and Societal Perspectives. Transportation Research Record, 2036, 1-9. https://doi.org/10.3141/2536-01 
[16] Google, Google Transit APIs (2016) https://developers.google.com/transit/

[17] Spieser, K., Treleaven, K., Zhang, R., et al. (2014) Toward a Systematic Approach to the Design and Evaluation of Automated Mobility-on-Demand Systems: A Case Study in Singapore. Road Vehicle Automation, Springer, Berlin, 229-245.

https://doi.org/10.1007/978-3-319-05990-7_20

Submit or recommend next manuscript to SCIRP and we will provide best service for you:

Accepting pre-submission inquiries through Email, Facebook, LinkedIn, Twitter, etc. A wide selection of journals (inclusive of 9 subjects, more than 200 journals)

Providing 24-hour high-quality service

User-friendly online submission system

Fair and swift peer-review system

Efficient typesetting and proofreading procedure

Display of the result of downloads and visits, as well as the number of cited articles

Maximum dissemination of your research work

Submit your manuscript at: http://papersubmission.scirp.org/

Orcontact jtts@scirp.org 